\title{
A CONSTITUIÇÃO DO PENSAMENTO AMBIENTAL: DE LEFF A INGOLD - BASES DA VISÃO CRÍTICA?
}

\author{
Aline de Fátima Santos Camara Cooper ${ }^{1}$ \\ Maylta Brandão dos Anjos ${ }^{2}$
}

Resumo: O presente artigo busca articular pressupostos teóricos levantados por Tim Ingold a apontamentos de Enrique Leff, com o intento de se configurar uma linha de pensamento ambiental com bases críticas mais integradas. São feitas, tanto por Ingold, quanto por Leff, diversas proposições que rompem as intransigentes visões encasteladas, que fragmentam a questão ambiental, construindo dogmas relacionados a uma visão higienizante, biologizante e reducionista desta, e afastando-a do seu real sentido humanitário, o da crítica social. Os autores recuperam questões preciosas, centrando luz na essencialidade humana, no conceito de ambiente e nas mediações sociais construídas em torno de sua (des)união.

Palavras-chave: Pensamento ambiental crítico. Tim Ingold. Enrique Leff.

\section{THE CONSTITUTION OF ENVIRONMENTAL THOUGHT: FROM LEFF TO INGOLD - BASIS OF A CRITICAL VISION?}

Abstract: This paper seeks to articulate theoretical assumptions raised by Tim Ingold to those created by Enrique Leff, looking for a line of critical environmental thinking with more holistic bases. Both, Ingold and Leff, make propositions that disrupt entrenched uncompromising visions and break environmental issues, building dogmas related to a sanitizing, biologizing and reductionist view of these issues, far away from its real humanitarian sense, the sense of social criticism. The authors recover precious issues, focusing light on the human essence, the concept of environment and social mediations built around their (dis)unity.

Keywords: Environmental critical thinking. Tim Ingold. Enrique Leff.

\section{LA CONSTITUCIÓN DEL PENSAMIENTO AMBIENTAL: LEFF A INGOLD - ¿BASE DE LA VISIÓN CRÍTICA?}

Resumen: En este trabajo se busca articular los supuestos teóricos planteados por Tim Ingold y las notas de Enrique Leff con la intención de establecer una línea de pensamiento ambiental con bases críticos más integrados. Ingold y Leff hacen varias proposiciones que rompen las inflexibles visiones arraigadas, que

\footnotetext{
1 Mestranda em Ensino de Ciências pelo Programa de Pós-Graduação Stricto Sensu em Ensino de Ciências do Instituto Federal de Educação, Ciência e Tecnologia do Rio de Janeiro. Docente de Ciências das redes municipais de ensino do Rio de Janeiro e de Angra dos Reis. cooper.aline@ gmail.com

${ }^{2}$ Doutora em Ciências Sociais pelo CPDA/ Universidade Federal Rural do Rio de Janeiro. Docente e pesquisadora do Programa de Pós-Graduação stricto sensu em Ensino de Ciências do Instituto Federal de Educação, Ciência e Tecnologia do Rio de Janeiro. maylta@ yahoo.com.br
} 
fragmentan las cuestiones ambientales, construyendo dogmas relacionados con una visión higienizante, biologizante y reduccionista, y lejos de su sentido humanitario verdadero, que es la crítica social. Los autores recuperan temas preciosos, enfocando la luz sobre la esencia humana, el concepto de medio ambiente y las mediaciones sociales construidas alrededor de su (des)unión.

Palabras-clave: Pensamiento Ambiental crítico. Tim Ingold. Enrique Leff.

\section{Introdução: a busca de uma visão mais integrada do pensamento ambiental}

Terra! Um dia comerás meus olhos...

Eles eram

No entanto

O verde único de tuas folhas

O mais puro cristal de tuas fontes...

Meus olhos eram os teus pintores! [...]

Mario Quintana

Para que possamos analisar a questão ambiental sob o aspecto crítico, há que se considerar os fundamentos dessa crítica, seja ela em um caminhar antropológico que se direcione às considerações culturais e sociais, como em Tim Ingold, ou, que aborde de maneira mais aprofundada os aspectos epistemológicos e políticos, como em Enrique Leff. Mesmo em diferentes caminhos, observamos que podemos transportar esse conceito da crítica para o que se tem configurado em autores consagrados no âmbito das discussões relacionadas ao pensamento ambiental como Philippe Pomier Layrargues, Mauro Guimarães e Carlos Frederico Loureiro. Grupo, este, que conversa entre si, pautado nas bases da crítica social ao modus operandis de produção.

Nesse sentido, Loureiro (2006, p.70) nos propõe, que, para a tradição crítica no âmbito ambiental, não cabe:

[...] discutir conservação sem considerar os processos sociais que levaram ao
atual quadro de esgotamento e extinção; falar em mudanças de
comportamentos sem pensar como cada indivíduo vive, seu contexto e suas
possibilidades concretas de fazer escolhas; defender uma forma de pensar a
natureza, ignorando como cada civilização, cada sociedade e cada
comunidade interagiam nela e definiam representações sobre ela; como
produziam, geravam cultura e estilos de vida e como isso se dá hoje.

Mauro Guimarães (2004), por sua vez, nos coloca que a reflexão crítica não deve se apoiar na estabilidade das certezas, do já conhecido, além de rechaçar uma visão simplificadora e reducionista da realidade e buscar os nexos contidos nas interações e inter-relações das partes com o todo e do todo com as partes.

Layrargues (2012, p.408) mostra um discurso completamente embebido por uma luta aberta contra o capitalismo, como em:

[...]a macrotendência Crítica, por conceber o problema ambiental associado ao conflito social e incluir no debate a compreensão dos mecanismos da reprodução social e de que a relação entre o ser humano e a natureza é mediada por relações socioculturais e de classes historicamente construídas, por apresentar uma abordagem pedagógica contextualizadora e problematizadora das contradições do modelo de desenvolvimento e dos mecanismos de acumulação do Capital, por lutar contra as formas de 
autoritarismo, opressão, exploração e domínio, por politizar o debate ambiental, articular as diversas dimensões da questão ambiental e sustentabilidade e por buscar o enfrentamento político por meio da pedagogia do conflito para a superação da desigualdade e injustiça ambiental, sua própria natureza parece ser a expressão político-pedagógica que mais se aproxima da radicalidade da crítica anticapitalista e da construção de um projeto societário alternativo.

A partir daí, passamos a tentar articular os pressupostos levantados por Tim Ingold aos apontamentos de Enrique Leff, na busca de uma linha de pensamento ambiental com bases críticas mais globais, que complemente o cabedal teórico instituído por inúmeros autores da área.

Tim Ingold, antropólogo britânico, buscou, em seus trabalhos iniciais, apresentar uma concepção do ser humano como um nexo singular de crescimento criativo dentro de um campo de desdobramento de contínuas relações.

A manutenção da vida, para o autor, não se concretiza com a criação de políticas públicas de preservação da vida, ou do meio ambiente, ou mesmo com campanhas de sensibilização e, menos ainda, de conscientização. Tal manutenção depende basicamente de uma nova dimensão do sentido da vida no mundo, de maneira orgânica (CASTAÑEDA, 2013).

O autor destaca a chamada wayfaring, uma concepção de vida que se dá ao longo de linhas ou fios e também traz à discussão questões relevantes à construção e compreensão de um pensamento ambiental crítico holístico, tais como: a primazia do movimento, a natureza e constituição do solo, as perspectivas divergentes da Terra como o local que habitamos e do planeta como algo distante, a relação da terra e do céu, do vento e do tempo, a fluidez e o atrito de materiais; as experiências de luz, som e sentimento, o que significa fazer as coisas, desenhar, escrever e contar histórias.

Ingold afirma que filósofos têm meditado longamente sobre a condição de se estar no mundo. Contudo, mover-se, conhecer e descrever, são ações que necessitam muito mais que uma imersão, um pertencimento ao ambiente. São ações que também primam pela observação. Um ser que se move, sabe e descreve deve estar atento. Sendo assim, ser observador significa estar vivo para o mundo.

As bases do pensamento crítico são fundadas na capacidade de julgar, de forma que nada é mais importante que observarmos, sendo seres vivos no mundo, para que possamos julgar e agir sobre o que nos cerca com maior propriedade.

Já Enrique Leff, economista mexicano tido como um dos pilares do pensamento ambiental crítico, nos propõe a indivisibilidade entre a problemática ambiental e a problemática democrática e, consequentemente, a conjugação da sustentabilidade ecológica com as demandas de equidade e justiça, pelo caminho de uma racionalidade produtiva alternativa, incorporando a esta última processos culturais e ecológicos.

Segundo Leff (2000), toda a formação social desenvolve-se numa estreita relação com seu entorno natural, porém, a integração da população humana ao seu meio ecológico está sempre condicionada por práticas culturais de aproveitamento dos recursos que mediam as inter-relações entre os processos ecológicos e os processos históricos.

O sistema capitalista rompeu a harmonia entre os sistemas naturais $\mathrm{e}$ as formações sociais. A implantação de modelos tecnológicos e culturais ecologicamente inapropriados, durante uma longa dominação colonial e imperialista, gerou uma irracionalidade produtiva, no sentido de um manejo ecológico e energético ineficiente e 
dos crescentes custos ambientais na produção de valores de uso e de mercadorias (LEFF, 2000, p.26).

Assim, desde o momento em que a natureza, de forma global, é afetada pelas relações sociais de produção os processos biológicos passam a ser determinados pelos processos históricos em que o homem ou a natureza se inserem (LEFF, 2001).

Leff (2010), da mesma maneira que Ingold, também considera que a disjunção entre o ser e o ente, no pensamento metafísico, foi seguida pela disjunção entre o objeto e o sujeito do conhecimento na ciência moderna. O sujeito tomado pela epistemologia e pela metodologia da ciência que nasce com Descartes, com o iluminismo da razão e com o humanismo da ilustração, tem a ideia forjada de que seja um sujeito autoconsciente e livre, fundamentando e ideologizando um individualismo metodológico da ciência, do sujeito transcendental do idealismo filosófico, do ator social da democracia e o indivíduo inovador do livre mercado, figuras, estas, das quais tanto se vangloria a sociedade moderna. Enrique Leff cita, ainda, Nietzsche, como o primeiro a identificar a crise desse sujeito forjado nos moldes do método cartesiano da ciência e do racionalismo kantiano do humanismo.

Ainda em Leff, há a proposição de que a emancipação do ser implica na necessidade de se descobrir, penetrar e desconstruir o fio condutor que liga a autoidentificação de si mesmo até a autoconsciência do sujeito; fio, este, que sustenta a estrutura da racionalidade que surge no cartesianismo e que se instaura no discurso da modernidade, moldando o sujeito, envolvendo-o e cegando-o.

\section{Tim Ingold - A produção, a história, a habitação e a vida em fios como tópicos importantes na compreensão de um pensamento ambiental holístico}

Para restaurar a vida à Antropologia, redirecionando o sentido e o trabalho desta última, Ingold nos coloca que seus esforços se concentraram em quatro fases, sendo que cada uma delas girou em torno de um único termo chave. A primeira fase foi sobre o significado da produção, a segunda foi sobre o significado da história, a terceira fase sobre a noção de habitação e, a última fase, teria sido a exploração da ideia de que a vida que se dá ao longo das chamadas linhas ou fios.

Um primeiro ponto importante gira em torno da questão do que significa a condição dos seres humanos enquanto os produtores de suas vidas. Contudo, tal indagação levou a outra: como é que, na produção de suas vidas, os humanos criam a história? E como se não bastasse, há a dúvida se tal história criada pelos humanos se distingue do processo evolutivo que envolve todos os seres vivos do planeta. Dessa forma, levando em consideração essa noção de história coletiva, surge a chamada perspectiva de habitação, uma forma de superar a divisão entre dois mundos entrincheirados: o da natureza e o da sociedade, dando ao ser humano a possibilidade de se perceber parte de um continuum no mundo da vida, sendo cada ser instanciado no mundo com um caminho de movimento.

Com relação à produção, utilizando pressupostos teóricos encontrados em Engels, Ingold (2011) nos afirma que, independentemente do impacto efetivo das suas atividades, os animais não trabalham em seu ambiente com o intuito de mudá-lo. Eles não têm a concepção de tarefa, mas os seres humanos, ao contrário, sempre trabalham com alguma noção do que estão fazendo, mesmo que os resultados não correspondam às expectativas. 
Há também Marx, citado para melhor compreendermos a questão da produção humana, que, por sua vez, " termina na criação de algo que, quando o processo começou, já existia ... de forma ideal" (MARX 1930, apud INGOLD, 2011). Para Marx, esse modelo de criação apresentado se constituía em um dilema, pois se a forma de uma coisa já deve existir na imaginação antes que o trabalho de produção possa sequer começar, fica difícil compreender de onde vem essa imagem inicial. Posteriormente, verificou-se que o consumo é que define tais imagens iniciais, dando os objetivos de produção. Tal fenômeno ocorre através da criação de expectativas sobre as formas que as coisas devem tomar e as funções que devem cumprir, e essas expectativas, por sua vez, motivam o processo produtivo. Além disso, Marx afirma também que não são apenas os materiais trabalhados que são transformados no processo de produção. $\mathrm{O}$ trabalhador também é alterado por meio da experiência. Potencialidades, antes latentes, de ação e percepção são desenvolvidas. Ele se torna, mesmo que muito ligeiramente, uma pessoa diferente. Daí, podemos supor que, talvez, a essência da produção humana encontra-se tanto ou mais na qualidade da atenção dada à ação - isto é, em sua sintonia e capacidade de resposta do trabalhador para com a tarefa que se desenrola - e seus efeitos no desenvolvimento do produto, como em todas as imagens ou representações dos fins a serem alcançados que possam previamente existir.

Ingold (2011, p. 6) nos coloca que a produção deve ser entendida intransitivamente, não como uma relação transitiva de imagem ao objeto. E deve, de uma vez por todas, restaurar a chamada "produção da primazia existencial", que envolve os processos de esperança, de crescimento e de habitação sobre as formas que são concebidas e realizadas dentro deles. A produção não deveria ser entendida como a transformação do mundo material, mas, sim, como a participação na transformação do mundo de si mesmo,

A partir dos pressupostos anteriormente tratados, o autor também nos traz a chamada teoria dos sistemas de desenvolvimento (developmental systems theory), para analisar o aspecto histórico, como uma forma de ultrapassar o dualismo constituído por duas histórias: a dos seres humanos e a do resto do mundo vivo. Com a referida teoria, é possível recolocar a experiência histórica dos seres humanos dentro das matrizes de evolução na qual todos os seres vivos estão imersos. Com relação a essas matrizes, o que há não é exatamente a interação entre dois tipos de história - no caso da história superior da humanidade, no plano da sociedade, e da história inferior, da natureza - mas uma história composta pela interação de diversos seres humanos e não humanos em seu envolvimento mútuo.

O conceito de habitação também é discutido por Ingold. Ele afirma que o caminho, e não o lugar, é a condição primordial do ser, ou melhor, de se tornar. Por essa razão, ele questiona se o conceito de habitação seria o mais adequado para descrever como os seres humanos e não humanos fazem seus caminhos no mundo. O que é demasiadamente interessante é que, para o autor o conceito de habitação carrega uma aura de localismo confortável, bem embrulhado, que parece fora de sintonia com ênfase na primazia do movimento. Assim, ele propõe o chamado wayfaring, que é o modo fundamental pelo qual os seres vivos habitam a Terra, podendo ser imaginado como a linha ou fio de seu próprio movimento ou - mais realisticamente - como um conjunto desses fios.

Finalmente, o entrelaçamento dessas trajetórias, desse conjunto de fios, compõe a textura do mundo (meshwork). Na ontologia anímica, os seres não ocupam o mundo simplesmente, eles habitam-no, e ao fazê-lo, configuram seus próprios caminhos na 
malha ambiental, contribuindo para que a sua trama esteja em constante evolução. Assim, diz Ingold, devemos parar de pensar no mundo como um substrato inerte, sobre o qual os seres vivos impulsionam-se como contadores em uma placa ou atores em um palco. Os seres que habitam o mundo não são meros objetos que se movem. O mundo anímico está em fluxo perpétuo e os seres dele participam de várias formas. Esses seres não existem em locais específicos, mas sim, ocorrem ao longo de caminhos. Cada participante desta rede segue um modo de vida particular e tece um fio através do mundo, definindo um "parlamento de fios" (INGOLD, 2007, p. 5). Assim concebida, tal estrutura tem o caráter não de uma entidade fechada para o exterior, que se situa no e contra o mundo, mas de um nó cujos fios constituintes, longe de estarem nele contidos, deixam rastros e são capturados por outros fios, outros nós.

O organismo não poder ser fechado ou limitado, pois se exibe constantemente em movimento, como uma linha que cresce e move-se em um caminho qualquer, enlaçando-se a outras linhas-organismos. Assim, viver é uma linha, que traça seu caminho sem especificidade de forma e sempre improvisando e permitindo mesclar-se. A manutenção da vida teria que passar por projetar e criar o ambiente onde a existência possa ocorrer e habitar. (INGOLD, 2000).

\section{Ingold em Leff, Leff em Ingold}

Temos tido cada vez mais contato com informações díspares sobre o que pode ser definido como ambiente. Tal conceito, muitas vezes midiaticamente criado, tem se revelado a nós através de imagens de paisagens, da fauna e de povos de todo o planeta, em inúmeros casos, com o acompanhamento de fatos e números montados para oferecer uma atraente, porém distante e impessoal mensagem. Estamos demasiadamente acostumados com essa forma de pensar sobre o ambiente que nos esquecemos de que este é, em primeiro lugar, o mundo em que vivemos e não o mundo que olhamos, observamos.

Tim Ingold (2011) nos convida a refletir sobre tal concepção distorcida e nos conclama a reconhecer que nós vivemos o nosso meio ambiente, somos parte dele. As proposições trazidas por Ingold sobre o ambiente encontram, em grande parte, ressonância e complementariedade na obra de Enrique Leff, pois, segundo este último, o ambiente não é ecologia, mas a complexidade do mundo, composta por um saber sobre as formas de apropriação deste e da natureza, através de relações de poder que se inscreveram nas formas dominantes do conhecimento.

O primeiro ponto a se destacar na proposta teórica de Ingold sobre o que podemos entender como ambiente é o que se relaciona à percepção ambiental. Segundo o autor, nós vemos com os olhos treinados pela nossa experiência de ver o que está acontecendo ao nosso redor, ouvir com os ouvidos afinados pelos sons que são importantes para nós, e contato com corpos que se acostumaram, pela vida que levamos, a certos tipos de movimento. Assim, o ambiente passa a ser definido pelo mundo como ele existe e assume um significado em relação ao próprio indivíduo (INGOLD, 2000).

A acepção de paisagem, dada por Ingold, permite enfatizar a dinâmica dos processos temporais e sociais que dão forma ao ambiente, ao mesmo tempo em que constituem e modificam os lugares e os modos de habitar, permitindo distanciar-se de uma visão objetificadora que tende a atribuir um sentido de externalidade ao sujeito humano em relação ao mundo. Assim, a paisagem passa a ser tida como lócus da relação do sujeito com o mundo (CARVALHO; GRUN; AVANZI, 2009). 
Como um segundo ponto, há a proposição da ideia de incompletude do ambiente, pois, segundo Ingold, os ambientes são forjados através das atividades de seres vivos, dessa maneira, enquanto a vida continuar, ele estará continuamente em construção. Daí, a totalidade indivisível de organismo mais ambiente, compondo não uma entidade limitada, mas um processo. Processo que também envolve a passagem do tempo. Ingold defende a chamada perspectiva de habitação, segundo a qual a paisagem se constitui como um registro, um testemunho permanente da vida e das obras de gerações passadas que a habitavam, e que, ao fazerem-no, deixaram nela algo de si mesmas.

Outro aspecto importante, abordado por Ingold, diz que o conceito de ambiente não deve ser confundido com o de natureza. Para o autor, a distinção entre ambiente e natureza corresponde à diferença de perspectiva entre vermos a nós mesmos como seres dentro de um mundo e como seres sem ele, ou seja, temos a tendência de pensarmos a natureza como algo externo. Tal condição de externalidade não é só relacionada à humanidade, como já observado, mas também à própria história. Uma vez que ambientes continuamente passam a existir e a se transformar no processo da nossa vida, nós os moldamos assim como eles nos moldam, sendo eles próprios fundamentalmente históricos.

Dessas proposições iniciais, destacadas por Ingold, emerge uma forte articulação com as ideias trazidas por Leff:

\begin{abstract}
O ambiente está integrado por processos, tanto de ordem física como social, dominados e excluídos pela racionalidade econômica dominante: a natureza superexplorada e a degradação socioambiental, a perda da diversidade biológica e cultural, a pobreza associada à destruição do patrimônio de recursos dos povos e a dissolução de sua identidade étnicas; a distribuição desigual dos custos ecológicos do crescimento e a deterioração da qualidade de vida. Ao mesmo tempo, o ambiente emerge como um novo potencial produtivo, resultado da articulação sinergética da produtividade ecológica, da inovação tecnológica e da organização cultural (LEFF, 2001, pág. 159).
\end{abstract}

Para Leff (2000a), o ambiente se constitui como um sistema produtivo fundado nas condições de estabilidade e produtividade dos ecossistemas e nos estilos étnicos das diferentes culturas que os habitam. A articulação de processos ecológicos, tecnológicos e culturais acabam por determinar as formas de apropriação e transformação da natureza, e gerar a chamada produtividade ecotecnológica sustentável. Para esse autor, a crise ambiental é um resultado do desconhecimento da lei de entropia, que tem levado o imaginário economicista a uma ideia e produção sem limites.

Dessa forma, a solução para tal crise não poderia basear-se no refinamento do projeto científico e epistemológico que tem levado ao desastre ecológico, à alienação do homem e ao desconhecimento do mundo, sendo imprescindível um caminho novo que leve a uma compreensão de cunho planetário, incorporando a incompletude do ser, o diálogo de saberes e interseção da subjetividade, dos valores e dos interesses nas tomadas de decisão e nas estratégias de apropriação da natureza (LEFF, 2001).

Ingold (2000) também se aprofunda na discussão que diz respeito à divisão entre natural e cultural. Tal rompimento é tido como lamentável pelo autor, que nos indica a necessidade de que essa divisão seja posta de lado se quisermos chegar ao cerne das percepções das pessoas sobre o mundo, partindo da premissa de que as formas de agir no ambiente também são formas de se perceber o mesmo. 
Com efeito, Ingold nos indica que a perspectiva da razão abstrata é um produto da composição de duas dicotomias: uma entre a humanidade e a natureza, e outra entre a modernidade e a tradição. O autor busca substituir a dicotomia da natureza e da cultura pela sinergia dinâmica do organismo e ambiente, a fim de recuperar uma verdadeira ecologia da vida. Tal ecologia da vida é baseada na compreensão do chamado organism plus environment (organismo mais ambiente). Em "Perceptions of Environment", discute-se que, para a ecologia convencional, o plus significa uma simples adição de uma coisa à outra, sendo que ambos têm a sua própria integridade, de forma totalmente independente de suas relações. Na verdade, no convencionalismo ecológico-biológico, o organismo é especificado genotipicamente, antes da sua entrada no ambiente, e o ambiente é especificado como um conjunto de restrições físicas antes da chegada dos organismos que possam preenchê-lo.

Porém, excluído da ecologia convencional, o chamado conteúdo cultural, por outro lado, é transmitido por meios não genéticos, normalmente alguma forma de aprendizagem por observação, que leva à replicação, nas mentes dos novatos, de representações que orientam a conduta dos mais experientes. Equipado com essas representações, os indivíduos recém-aculturados podem ir para fora, para o mundo em que eles vão encontrar diversas condições ambientais, fazendo com que os seus conhecimentos se expressem de uma forma ou de outra, nas sutis variações e idiossincrasias dos comportamentos previamente observados.

Infere-se, então, que uma abordagem corretamente ecológica do ambiente seria aquela que tomaria como ponto de partida todo-organismo-em-seu-ambiente. Em outras palavras, organismo mais ambiente deve denotar não um composto de duas coisas, mas uma totalidade indivisível (INGOLD, 2000).

Leff, corroborando a ideia de Ingold sobre o que poderia constituir uma abordagem ecológica do ambiente, mais holística, propõe a concepção do chamado saber ambiental, constituído através da desconstrução dos paradigmas dominantes do conhecimento e pela produção e articulação de saberes, para construir novas racionalidades sociais possíveis.

O abandono do paradigma científico hegemônico e da emergência de um novo paradigma, cujas proposições são mais integradas, é ponto de forte encontro entre as ideias de Leff e de Ingold.

Esta perspectiva ambiental do conhecimento, ao romper com o projeto unitário de ciência - de sua formalização e matematização como critérios últimos de legitimação do conhecimento - abre a construção de um saber ambiental que transforma conhecimentos, gera novos sentidos e produz verdades que mobilizam a reconstrução da realidade, libertando processos naturais e sociais que permaneceram subjugados e agrilhoados pela racionalidade cientifica, tecnológica e econômica dominante (LEFF, 2000, p.179).

Porém, o primeiro grande obstáculo enunciado por Ingold para a efetivação da referida mudança do paradigma ecológico tem relação com a situação problemática da biologia. Mesmo os antropólogos que prontamente aceitam a ideia de personificação como um paradigma para o estudo da cultura, e que renunciam à distinção entre mente e corpo, tendem a recusar as tentativas de se amenizar a dicotomia convencional entre cultura e biologia. Ingold diz que a dicotomia continua tão forte como antes, só o corpo foi reposicionado. Anteriormente, colocado com o organismo no lado da biologia, o corpo reapareceu agora como um sujeito, no lado da cultura. 
O segundo obstáculo relaciona-se às dificuldades em se dissolver a fundo a divisão entre corpo e mente, pois o que ocorre é, na verdade, a ênfase de um termo com a exclusão do outro. Corpo e mente, afinal, não são duas coisas separadas, mas duas maneiras de descrever a mesma coisa - ou melhor, o mesmo processo - ou seja, a atividade ambientalmente situada do organismo pessoa humana.

Ingold afirma, ainda, que há que se reconhecer, atualmente, que processos como pensar, perceber, lembrar e aprender devem ser estudados dentro dos contextos ecológicos de inter-relações das pessoas com seus ambientes. Além disso, devemos reconhecer que a mente e as suas propriedades não são configuradas antes da entrada do indivíduo no mundo social, mas através de uma história ao longo da vida de envolvimento em relações com os outros. Os processos psicológicos e sociais são, portanto, uma mesma coisa.

Leff (2001), por sua vez, também aponta que, no processo de constituição do saber ambiental e do estabelecimento do novo paradigma ecológico, há diversas vias de complexificação do real (o entrelaçamento das ordens física, biológica e cultural; a hibridação entre a economia, a tecnologia, a vida e o simbólico) e do conhecimento (diálogo de saberes e hibridação entre ciências e tecnologias), das interpretações (ambiente como um campo heterogêneo e conflitivo, no qual se confrontam saberes e interesses diferenciados), da produção (reconhecimento do ambiente como um potencial produtivo, fundado na capacidade produtiva de valores de uso naturais que geram os processos ecológicos), do tempo (o saber ambiental constitui o entrecruzamento de tempos que têm configurado as concepções e as teorias sobre o mundo, e as cosmovisões das diversas culturas através da história), das identidades (mundo configurado por uma diversidade de identidades, que constituem formas diferenciadas do ser e entranham os sentidos coletivos dos povos) e do ser (confluência de processos e de tempos que rompeu a complexidade ecossistêmica e erodiu sua fertilidade; que subjugou as identidades múltiplas da raça humana e alienou as consciências).

A partir do forçamento da razão e do real, emerge a força da complexidade, a sinergia do encontro do ser complexo do mundo onde se enlaçam tempos, onde se entretecem identidades, onde se amalgamam culturas, onde se hibridizam a natureza, a cultura e a tecnologia, onde se bifurcam processos com sentidos diversos até a diferenciação do ser. (LEFF, 2001, p.217).

Outro conceito polêmico que envolve a ecologia da vida, proposta por Ingold, é o relacionado à matéria. Em "Being Alive” (2011), há a proposição de que o conceito abstrato de materialidade impediu a compreensão adequada do que chamamos de matéria. Deveríamos saber mais sobre como ela circula, mistura-se, solidifica-se e dissolve-se na formação de coisas mais ou menos duradouras, pois os materiais estão ativos. Só colocando tais materiais dentro de objetos fechados é que estes são reduzidos à matéria morta ou inerte. É essa tentativa de gabinete que deu origem ao chamado problem of agency (problema de atividade). Se fôssemos meros pedaços de matéria, não poderíamos fazer nada. Dessa maneira, Ingold propõe a existência de um ingrediente extrarresponsável por animar nossos corpos, que ele chama de agency. E se, como às vezes parece-nos, os objetos podem agir de volta, então esse ingrediente deve ser atribuído a eles também. Esta seria, supostamente, causa que levaria a matéria inerte ao movimento.

É isso que nos leva a supor que os seres humanos vivam alternadamente no interior e no exterior de um mundo material. Ingold (2011) cita, como ilustração, o exemplo da pedra. Podemos tocar a pedra, seja de uma parede da caverna ou do chão 
sob os pés e, assim, obter uma sensação de que a pedra é composta por um material. Contudo, não podemos tocar a materialidade da mesma.

A superfície da materialidade, em suma, é uma ilusão. Como todas as outras criaturas, os seres humanos não existem no outro lado da materialidade, mas, sim, nadam em um oceano de materiais. Uma vez que reconhecemos a nossa imersão, o que esse oceano nos revela não é a homogeneidade branda de diferentes tons de matéria, mas um fluxo em que os materiais dos mais diversos tipos, através de processos de mistura e destilação, de coagulação e dispersão, e de evaporação e precipitação, se submetem, em uma contínua transformação.

As they swim in this ocean of materials, human beings do of course play a part in their transformations. So, too, do creatures of every other kind. Organisms and persons, then, are not so much nodes in a network as knots in a tissue of knots, whose constituent strands, as they become tied up with other strands, in other knots, comprise the meshwork (INGOLD, 2011, p.24).

Dessa forma, perceber o ambiente não é simplesmente olhar para as coisas que podem ser encontradas no mesmo, ou a discernir suas formas e layouts congelados, mas se juntar a eles nos fluxos de materiais e movimentos que contribuem para a sua - e nossa - formação permanente.

Leff (2001) também nos aponta que a evolução do ser traz em si a emergência de formas diferentes de organização da matéria e do pensamento, que não podem ser reduzidas a um monismo ontológico, baseado simplesmente na generalização de princípios ecológicos de organização da matéria.

Por fim, Ingold (2011) lança uma reflexão em torno de duas proposições: o que é um ser humano e o que significa ser um humano. Primeiramente, poderíamos dizer que os seres humanos compreendem coletivamente uma espécie animal terrestre, cujas vidas e meios de subsistência estão necessariamente ligados às potencialidades e limitações do mundo material. Como outros organismos vivos, são feitos do mesmo material presente no mundo, pisam o mesmo chão e respiram o mesmo ar.

Contudo, quando tratamos do que significa ser um humano, estamos inclinados a responder que tal ser é o que está acima e além dos limites da natureza à qual a vida de todas as outras criaturas está vinculada.

É através do poder da razão e de seu eventual triunfo sobre a nossa própria natureza interna e a natureza que nos rodeia, que podemos dizer, que a essência de nossa humanidade se encontra. Realiza-se, historicamente, na ascensão da civilização e no avanço concomitante da ciência.

Ingold critica fortemente as ideias racionalistas e humanistas que definem o humano e se apoia na fenomenologia de Heidegger, assim como Leff, traçando uma relação desta com o pensamento kantiano, que envolve a forma de ver o mundo como uma superfície sobre a qual é possível localizar todos os conceitos deste, incluindo o de ser humano. Para Heidegger (apud LEFF, 2010, p.155), este modelo de Kant "expulsa a vida (e homens) da Terra", e, em contrapartida, propõe pensar-se o mundo da vida como um espaço do interior dos próprios seres vivos.

En el imperialismo planetario del hombre técnicamente organizado, el subjetivismo del hombre alcanza su cima más alta, desde la que descenderá a instalarse en el llano de la uniformidad organizada. Esta uniformidad pasa a ser el instrumento más seguro para el total dominio técnico de la tierra. La libertad moderna de la subjetividade se sume por completo en la objetividad 
adecuada a ella. El hombre no puede abandonar por sus propias fuerzas ese destino de su esencia moderna ni tampoco puede quebrarlo por medio de un acto de autoridad. Pero el hombre puede meditar previamente y concluir que el ser sujeto de la humanidad nunca ha sido ni será jamás la única posibilidad que se le abre a la esencia recién iniciada del hombre histórico (HEIDEGGER apud LEFF, 2010, p. 155).

Ingold argumenta que nós, seres humanos acabamos por nos tornar os exmoradores da Terra, expulsos do mundo (globo) de vida. Tal expulsão significa, dentre outras coisas, a fragmentação do conhecimento sobre a vida nas seguintes dualidades: ciências sociais e ciências naturais, ciências culturais e ciências ambientais. Essa fragmentação nos induz ao pensamento de que o meio ambiente é um e os seres humanos são outros, separados, impedindo a possibilidade de se considerar que os seres humanos são parte da vida, estão dentro do mundo.

Com a tradição kantiana, a busca pela transcendência da razão sobre a natureza proporciona à ciência uma plataforma de supremacia da qual, com não pouca arrogância e profunda contradição, afirma que os seres humanos são parte integrante do mundo natural. A partir de tal proposição, Ingold nos coloca um interessante paradoxo: os seres humanos, sendo parte da natureza, poderiam se encontrar acima da mesma, ao mesmo tempo?

Em uma reflexão mais aprofundada, no entanto, parece que o próprio significado de ser humano sintetiza essa contradição: nem uma espécie da natureza, nem a uma condição de ser que transcende esta última, mas, sim, de ambos simultaneamente. Humano é uma palavra que aponta para o dilema existencial de uma criatura que pode conhecer a si mesmo e ao mundo do qual faz parte somente através da renúncia de seu próprio ser nesse mundo.

Para encontrarmos um caminho que possa nos levar a superar o impasse gerado pela contradição relatada acima, temos que reconhecer que nossa humanidade não é nem algo relacionado com o território, com a nossa natureza específica de espécie, nem com uma possível condição imaginária que coloca o território fora de nós mesmos, mas com o processo histórico de nossa mútua e coletiva autocriação.

O que somos, ou o que podemos ser, é algo que nós continuamente moldamos através de nossas ações, contudo, tais ações também moldam a Terra, pela qual somos responsáveis. A forma da Terra emerge, seja na imaginação ou no chão, ou ambos ao mesmo tempo, por meio de nossas próprias práticas de habitação.

A Terra não é nem um objeto no espaço, nem um espaço para objetos, nem uma bola redonda, nem uma base plana. Ela permanece continuamente crescendo e brotando, como uma mistura de fluxos de materiais, atividades práticas, observações perspicazes e histórias pessoais, e sua forma é tecida a partir de todos esses componentes.

A complexidade ambiental, segundo Leff, não deve se limitar à compreensão da evolução natural da matéria e do homem até o encontro com o chamado mundo tecnificado. Tal compreensão deve se estender sobre o ser no saber, indo além da racionalidade dialógica, da dialética da fala e da escuta, da disposição para compreender e para se colocar no lugar do outro. Somente assim há a possibilidade de sairmos do âmbito do ecologismo naturalista e buscarmos o ambientalismo como política do conhecimento, no campo do poder embutido no saber ambiental, num projeto de reconstrução social a partir do reconhecimento da alteridade.

Enrique Leff (2010), em seu texto intitulado El Desvanecimiento del Sujeto y la Reinvención de las Identidades Colectivas en la Era de la Complejidad Ambiental, tenta 
desconstruir o sujeito construído pelo individualismo metodológico da ciência e que levou à objetivação da natureza, na construção da racionalidade e da modernidade. Defende a ideia de que os sujeitos vão se emancipando de tal configuração por um processo de reinvenção das identidades na complexidade ambiental. $\mathrm{O}$ ser individual passa a ter uma identidade de ser coletivo, um ser cultural. Então, emergem novos atores sociais guiados por uma racionalidade ambiental para a construção de um mundo sustentável, levando heterogênese da diversidade por um diálogo de saberes, em uma ética da alteridade e uma política da diferença.

A mudança no paradigma ecológico para Ingold (2000) também pressupõe a existência de um sujeito implicado na relação de conhecimento, recusando a ideia cartesiana de um sujeito da razão, observador, situado em algum lugar fora do mundo. Consiste, também, numa condição sine qua non a perspectiva de engajamento no mundo que, através das paisagens, deixa de ser o pano de fundo onde a ação acontece para ser, ele mesmo, um feixe de ações articuladoras do encontro humano e não humano, ou ainda uma trama - no sentido da tecelagem e do drama - desse encontro como mútua inscrição das marcas humanas no ambiente e deste na experiência humana do mundo (CARVALHO; GRUN; AVANZI, 2009).

Da complexidade ambiental emergem identidades híbridas que se baseiam em uma nova relação entre o real e o simbólico, entre o ser do mundo e o ser no mundo, na relação de um ser com outro, no encontro de seres culturalmente distintos e diversos. A reinvenção das identidades é um reposicionamento do ser no mundo, mundo, este, invadido e congestionado pela imposição de uma racionalidade que subjulga a própria vida (LEFF; ELIZALDE, 2010).

\section{Considerações finais: diferentes caminhos, um mesmo caminhar}

O tom antropológico que Ingold empresta à questão ambiental soma aos desdobramentos necessários aos diálogos que se estabelecem para pensar essa questão. São colocados, tanto por Ingold, quanto por Leff, pressupostos, que rompem as intransigentes visões encasteladas que fragmentam o tema, que constroem dogmas do que não o deveria ser, como exemplo o fortalecimento às práticas de reciclagem em detrimento às práticas de redução, reutilização, reflexão, sentido humanitário da questão e a crítica social. Os autores recuperam questões preciosas, centrando luz na essencialidade humana, no conceito de natureza e nas mediações sociais construídas em torno dessa (des)união.

Dessa forma, a constituição e a concretude da questão ambiental vão além das questões subjetivas e objetivas que conhecemos. O eixo condutor desse pensamento é, incomensuravelmente integrado, conectado, dialogizado. Destarte, é construção incessante que leva a pensar a dinâmica socioambiental. É na construção dialética, política, cultural e social que a questão ambiental vai se constituindo, que vai ganhando terrenos antes não pensados, vai rompendo dogmas e trazendo elementos de discussões pivotais que enriquecem e refinam, não somente a teoria, mas, sobretudo, a práxis proposta pela temática. A leitura nos autores suscita outras inspirações, que fazem pontes entre o que conhecemos na experiência sensorial e no que construímos em nossas abstrações. Assim, seus textos, ainda que não tenha sido esse o propósito, vêm recheados de verdade instrumental que enleva a questão ambiental, destituindo-a do pensamento do senso comum, da fragmentação e da disciplinarização do saber. 
Tanto Ingold quanto Leff, embora com a diversidade colocada em suas falas, demonstram ter uma unidade conceitual. O ambiente visto de forma ampla, conecta, responsável e, sobretudo, considerando que somos construtores e fazedores de política e cultura. Assim, os atributos da EA Crítica aparecem na clareza do discurso e seu reverso aponta outros caminhos que nos levam à questão da EA Conservadora.

\section{Referências}

CARVALHO, I. C. M.; GRUN, M.; AVANZI, M. R. Paisagens da compreensão: contribuições da hermenêutica e da fenomenologia para uma epistemologia da educação ambiental. Cad. CEDES, Campinas, v.29, n.77, p. 99-115, Apr. 2009 . Disponível em: < http://www.scielo.br/scielo .php?pid=S0101-32622009000100007\&script=sci_arttext $>$. Acesso em: 25 nov. 2014.

CASTAÑEDA, C. Tim Ingold, Ambientes para la vida. Tabula Rasa, Bogotá, n.18, p.303-307, Ene./Jun. 2013. Disponível em:<http://www.scielo.org.co/pdf/tara/n18/n18a16.pdf >. Acesso em: 10 mar. 2014.

GUIMARÃES, M. A formação de educadores ambientais. Campinas: Papirus, 2004.

INGOLD, T. The perception of environment: essays on livelihood, dwelling and skill. London: Routledge, 2000.

INGOLD, T. Lines: a brief history. London: Routledge, 2007.

INGOLD, T. Being alive: essays on movement, knowledge and description. Oxford: Routledge, 2011.

LAYRARGUES, P. P. Para Onde vai a Educação Ambiental? O Cenário Político-Ideológico da Educação Ambiental Brasileira e os Desafios de uma Agenda Política Crítica Contrahegemônica. Revista Contemporânea Educação, Rio de Janeiro, v.7, n.14, p.398-421, Ago./Dez. 2012. Disponível em:

<http://www.revistacontemporanea.fe.ufrj.br/index.php/contemporanea/article/view/410/240> Acesso em: 18 nov. 2014.

LEFF, E. Ecologia, Capital e Cultura: Racionalidade Ambiental, Democracia Participativa e Desenvolvimento Sustentável. Blumenau: EDIFURB, 2000.

LEFF, E. Saber Ambiental: sustentabilidade, racionalidade, complexidade, poder. Petrópolis: Vozes, 2000a.

LEFF, E. El desvanecimiento del sujeto y la reinvención de las identidades colectivas en la era de la complejidad ambiental. Polis, Santiago, v.9, n.27, p.2-33, Dic. 2010. Disponível em: <http://polis.revues.org/862?lang=pt >. Acesso em: 25 nov. 2014.

LEFF, E. Epistemologia Ambiental. São Paulo: Cortez, 2001.

LEFF, E. ELIZALDE, A. Sujeto, subjetividad, identidad y sustentabilidad. Polis, Santiago, v.9, n. 27, p.2-6, Dic. 2010. Disponível em: <http://polis.revues.org/290 >. Acesso em: 25 nov. 2014. 
LOUREIRO, C. F. Educação ambiental e teorias críticas. In: GUIMARÃES, M. (Org.).

Caminhos da educação ambiental: da forma à ação. Campinas: Papirus, 2006. p.51-86.

MARX, K. Capital, Vol. 1, trans. E. Paul and C. Paul. 1930. London: Dent. In: INGOLD, T. Being alive: essays on movement, knowledge and description. Oxford: Routledge, 2011

Artigo recebido em 23/03/2014

Aceite em 20/10/2014 